\title{
IN VITRO CAPACITATION OF HAMSTER SPERMATOZOA BY FOLLICULAR FLUID
}

\author{
R. YANAGIMAGHI \\ Department of Anatomy, University of Hawaii School of Medicine, \\ Honolulu, Hawaii, U.S.A.
}

(Received 11th March 1968)

\begin{abstract}
Summary. When hamster epididymal spermatozoa were incubated in vitro in the presence of follicular fluid in Tyrode's solution for $3 \mathrm{hr}$ or more, they became fully capacitated. The majority of the capacitated spermatozoa had lost the acrosome cap, and they displayed an extremely vigorous motility. When placed in contact with freshly ovulated eggs in vitro, the spermatozoa started to enter the zona pellucida of the eggs as early as $10 \mathrm{~min}$ after insemination; sperm penetration through the zona pellucida, however, occurred most often between 30 and $50 \mathrm{~min}$ after insemination. The follicular fluid markedly reduced its spermcapacitating potency when diluted with a large volume of Tyrode's solution. Cumulus oophorus cells, their matrix, corona radiata cells and the eggs had no potency to induce functional capacitation of the spermatozoa. Follicular fluids of four different species were tested. In respect to their potency to capacitate hamster spermatozoa, the fluids of three species could be arranged in the following order: hamster $>$ mouse $>$ rat. Rabbit follicular fluid was totally ineffective.
\end{abstract}

\section{INTRODUCTION}

At ovulation a large volume of follicular fluid is released from mature ovarian follicles. At least a part of this fluid must be transported into the oviduct together with the cumulus oophorus containing the eggs. Recently, Barros \& Austin (1967a) reported that hamster ovarian eggs recovered from mature follicles shortly before ovulation could be fertilized in vitro when incubated with epididymal spermatozoa in the presence of follicular fluid. This suggests that follicular fluid may induce functional capacitation of the spermatozoa without the contribution of oviduct and uterine factors. Barros \& Austin (1967b) further reported that follicular fluid had a stronger capacity to induce the acrosome reaction of spermatozoa than oviduct fluid. This paper deals with the capacitation of hamster epididymal spermatozoa by follicular fluid under several experimental conditions and the species-specificity of capacitation by follicular fluid. 


\section{MATERIALS AND METHODS}

Control of ovulation time

Young adult golden hamsters weighing 100 to $140 \mathrm{~g}$ were given an intraperitoneal injection of 20 to 30 i.u. of PMSG (Ayerst) between 09.00 and 11.00 hours of Day 1 (the day on which post-oestrous discharge was found in the vagina), followed by intraperitoneal injection of 20 to 30 i.u. of HCG (Ayerst) between 12.00 and 24.00 hours of Day 3. Ovulation occurred consistently between 11 and $14 \mathrm{hr}$ after the HCG injection. Twenty to fifty eggs were ovulated in one female. When PMSG treatment was omitted, an average of ten eggs were ovulated per female.

Female rats (Fisher, 120 to $150 \mathrm{~g}$ ) and mice (Swiss Albino, 30 to $40 \mathrm{~g}$ ) were each injected intraperitoneally with 20 to 30 i.u. of PMSG (rat) or with 10 i.u. of PMSG (mouse), regardless of the stage of their oestrous cycle, followed after 48 hr by an intraperitoneal injection of 20 to $30 \mathrm{i} . u$. of HCG (rat) or $10 \mathrm{i.u}$. of HCG (mouse). Ovulation occurred between 11 and $14 \mathrm{hr}$ after the HCG injection.

In the rabbits (New Zealand White), ovulation was induced by intravenous injection of 25 i.u. of HGG. Ovulation commenced at about $10 \mathrm{hr}$ after the HCG injection.

\section{Preparation of sperm suspension}

A cauda epididymidis of a fertile hamster male was excised and the blood adhering to the surface was removed with a piece of dry, sterile filter paper. The wider end of the epididymis was then incised at a few or several places and a dense mass of spermatozoa was squeezed out. A mass of spermatozoa, about 0.3 to $0.5 \mathrm{ml}$ in volume, was put at the centre of a watch glass $6.5 \mathrm{~cm}$ in diameter) and immediately covered with 3 to $4 \mathrm{ml}$ of Tyrode's solution. One to 3 min later, a portion of the Tyrode's solution in which spermatozoa were actively swimming was drawn into a tuberculin syringe (without needle). The concentration of spermatozoa in the suspension was not strictly controlled, but it was usually 16,000 to 27,000 spermatozoa per $\mathrm{mm}^{3}$. Only suspensions in which more than 60 to $80 \%$ of the spermatozoa were displaying an active progressive movement were used.

\section{Recovery of follicle contents (follicular fluid and cumulus oophorus containing eggs)}

Between $9 \frac{1}{2}$ and $10 \frac{1}{2} \mathrm{hr}$ after HCG injection, the ovaries of hamsters, rats and mice were excised from the females and rolled gently over a dry, sterile filter paper to remove blood adhering to their surfaces. An ovary was then placed at the centre of a small watch glass $(3.8 \mathrm{~cm}$ in diameter), immediately covered with 1.0 to $1.5 \mathrm{ml}$ of mineral oil (Squibb \& Co.), and the apices of fifteen to twenty large mature follicles were broken by means of a silicon-coated, sharp needle. Follicle contents that oozed out of the follicles were accumulated at the centre of the watch glass. The spent ovary, tissue debris and blood were carefully removed with forceps or a small-bore pipette.

The same procedures were applied for the recovery of the contents of rabbit follicles between 5 and $9 \mathrm{hr}$ after HCG injection. 
Incubation of spermatozoa with follicle contents

Spermatozoa were incubated with follicle contents for up to $12 \mathrm{hr}$ at $37^{\circ} \mathrm{C}$ in the following five different ways:

Type I. A drop of sperm suspension was introduced, through a No. 25-gauge needle attached to a tuberculin syringe, into the mineral oil over the follicle contents in a watch glass. The drop of sperm suspension and the follicle contents were then mixed thoroughly with a needle. The volume of the sperm suspension thus introduced was 0.005 to $0.01 \mathrm{ml}$, about 1 to 2 times the volume of the mass of follicle contents under the oil. When examined 10 to 15 min after the mixing, the cumulus oophorous cells surrounding the eggs were found to be completely dispersed. Corona radiata cells, on the other hand, were still attached to the zona pellucida of the eggs; they, however, were eventually detached from the zona pellucida during further incubation of the preparation. Thus, in this type of incubation the following follicular components were present in the medium: follicular fluid, cumulus oophorus cells, dissolved matrix (hyaluronic acid complex) of cumulus cells, corona radiata cells, and eggs.

Type II. A mass of follicle contents recovered under the mineral oil was thoroughly mixed with a drop of sperm suspension using the same procedures as described above. Ten to $20 \mathrm{~min}$ after the mixing, the eggs which were still surrounded by corona radiata cells were removed by means of a small-bore pipette. The sperm-incubating medium, therefore, contained follicular fluid, and cumulus oophorus cells and their dissolved matrix.

Type III. After the follicle contents had been placed under the mineral oil, the cumulus oophorus masses containing the eggs were removed, thus leaving only follicular fluid under the oil. The follicular fluid was then mixed with a drop $(0.005$ to $0.01 \mathrm{ml})$ of sperm suspension (Type IIIa). In some experiments, the follicular fluid was diluted with $0.03 \mathrm{ml}$ of Tyrode's solution (Type IIIb) or with $0.1 \mathrm{ml}$ of Tyrode's solution (Type IIIc) before being mixed with a drop of sperm suspension. Thus, the spermatozoa were incubated in the medium containing follicular fluid only.

Type IV. Follicular contents were released from mature follicles into $5 \mathrm{ml}$ of Tyrode's solution. Fifteen to twenty cumulus masses containing eggs were transferred from one Petri dish with $5 \mathrm{ml}$ of Tyrode's solution to another, three times, thus rinsing out all the follicular fluid present around the cumulus. These cumulus masses were then suspended in a small drop $(0.005$ to $0.01 \mathrm{ml})$ of fresh Tyrode's solution, placed under mineral oil in a watch glass, and mixed with a drop $(0.005$ to $0.01 \mathrm{ml})$ of sperm suspension. Thus, in this type of incubation, cumulus oophorus cells, their dissolved matrix, corona radiata cells and eggs were present around the spermatozoa during incubation.

Type $V$. Using the same procedures as described above, fifteen to twenty cumulus masses were mixed with a drop of sperm suspension. After the cumulus oophorus cells had been dispersed (in 10 to $15 \mathrm{~min}$ after the mixing), the eggs with corona radiata cells were removed, thus leaving cumulus oophorus cells and their dissolved matrix in the incubation medium.

All the procedures involved in preparation of sperm suspension, recovery of follicle contents and mixing of follicle contents with sperm suspension were carried out in a sterile shield at $25^{\circ}$ to $35^{\circ} \mathrm{C}$. All glassware and instruments used 
had been sterilized by either autoclaving or dry heating. Tyrode's solution was sterilized through a Millipore filter before use.

\section{Examination of motility and acrosome of incubated spermatozoa}

At various hours after the start of incubation, a watch glass with incubated spermatozoa was transferred from the incubator $\left(37^{\circ} \mathrm{C}\right)$ on to the stage of a microscope $(10 \times 10)$ for the examination of motility of the spermatozoa. A portion of the medium in which the spermatozoa were swimming was then mounted between a slide and a coverslip, and examined with a phase-contrast microscope $(40 \times 10)$ for the morphology of the acrosome. In each experiment, over sixty vigorously motile spermatozoa were examined, and the number of spermatozoa without visible acrosomes (not perceptible with a phase-contrast microscope) was recorded. The spermatozoa with either apparently intact acrosomes or altered (elevated, shrunken or crumpled) acrosomes were recorded as having acrosomes. No attention was directed towards immotile spermatozoa, because the acrosome of hamster spermatozoa may undergo post mortem disintegration or detachment (Austin \& Bishop, 1958a).

\section{Evaluation of sperm capacitation}

In the hamster, epididymal spermatozoa never penetrate the eggs earlier than 3 to $4 \mathrm{hr}$ after being deposited in the female genital tract. Even when they are directly put around the eggs in vitro (in the presence of oviduct fluid), they never penetrate the eggs in less than 3 to $4 \mathrm{hr}$ (Yanagimachi, 1966). In the present study, capacitation of spermatozoa was evaluated by examining the penetration of eggs by spermatozoa at 60 to $70 \mathrm{~min}$ after in vitro insemination. If the majority of eggs was found to be penetrated by this time, the spermatozoa were considered fully capacitated before insemination. The methods used for insemination of eggs and subsequent examination of sperm penetration are described below.

At the end of various incubation periods, five to twenty freshly ovulated eggs (recovered from the oviduct of a female at 15 to $16 \mathrm{hr}$ after HCG injection) were introduced into the medium containing incubated spermatozoa. When spermatozoa had been incubated by either Type I or Type IV incubation, eggs were already present in the medium. Such eggs were removed before introducing the freshly ovulated eggs. After the eggs had been incubated with spermatozoa for 60 to $70 \mathrm{~min}\left(\right.$ at $\left.37^{\circ} \mathrm{C}\right)$, they were mounted between a slide and a coverslip supported by four vaseline drops. By moderately pressing the eggs under the coverslip, spermatozoa in the eggs, if present, could be clearly seen (Yanagimachi \& Chang, 1964; Yanagimachi, 1966). The exact location of spermatozoa within the egg was determined by focusing through the depth of the egg from one surface to the other. Rotation of the egg under the coverslip made it possible to determine the exact position of each spermatozoon in the egg. An egg was recorded as being 'penetrated' when the head of at least one spermatozoon was found in the perivitelline space, or on or in the vitelline surface, or a swollen sperm head or a male pronucleus was discernible in the vitellus. Eggs which did not fall into this category were recorded as 'unpene- 
trated', no matter how many spermatozoa were in the act of penetration through the zona pellucida.

\section{RESULTS}

Effect of incubation time on the motility, acrosome reaction and capacitation of spermatozoa

Spermatozoa were incubated with hamster follicle contents for $\frac{1}{2}$ to $12 \mathrm{hr}$, using Type II incubation. At the end of various incubation periods, the spermatozoa were examined for their (1) motility, (2) morphology of the acrosome, and (3) capacity to penetrate eggs within 60 to $70 \mathrm{~min}$. The results obtained are summarized in Table 1.

Incubation for less than $1 \mathrm{hr}$. At the moment when the spermatozoa were mixed with follicle contents, the majority $(60$ to $90 \%$ ) of them displayed an active progressive movement. During the first $\frac{1}{2}$ to $1 \mathrm{hr}$, however, a large proportion of the spermatozoa (sometimes about one half of all the spermatozoa) lost their motility completely. All the motile spermatozoa during this period had apparently intact acrosomes. None of these spermatozoa could penetrate the eggs within 60 to $70 \mathrm{~min}$.

Incubation for $1 \frac{1}{2}$ to $2 \mathrm{hr}$. Toward the end of the 2-hr incubation period, extremely active spermatozoa appeared among the motile spermatozoa. Some of these spermatozoa (1.3\% of all the motile spermatozoa) had no visible acrosomes. The spermatozoa could penetrate about one-sixth (ranging from 0 to $53 \%$ ) of the eggs within 60 to $70 \mathrm{~min}$.

Incubation for $3 \frac{1}{2}$ to $6 \mathrm{hr}$. When the spermatozoa had been incubated for $3 \frac{1}{2}$ to $6 \mathrm{hr}$, a large number of them displayed an extremely active movement. The proportion of vigorously motile spermatozoa reached a maximum when spermatozoa had been incubated for 4 to $5 \mathrm{hr}$. The movement of these spermatozoa was so vigorous that the detailed examination of their heads could not be done in many cases until the temperature of the sperm-suspending medium was reduced $\left(37^{\circ} \mathrm{C} \rightarrow 20^{\circ} \mathrm{C}\right.$ or below). Close examination showed that most of these vigorously motile spermatozoa had no visible acrosomes. The spermatozoa incubated for 4 to $6 \mathrm{hr}$ could consistently penetrate 70 to $100 \%$ of the eggs within 60 to $70 \mathrm{~min}$.

Incubation for $11 \frac{1}{2}$ to $12 \mathrm{hr}$. A large proportion (80 to $90 \%$ ) of the spermatozoa were immotile when examined after $11 \frac{1}{2}$ to $12 \mathrm{hr}$ incubation. Most of the surviving spermatozoa, however, were still vigorous. The acrosome was invisible in most of them. The spermatozoa could penetrate less than one-sixth of the eggs within 60 to $70 \mathrm{~min}$.

From these results the following deductions may be drawn: (1) the optimum incubation time for the induction of full capacitation of hamster epididymal spermatozoa by follicle contents is 3 to $6 \mathrm{hr}$; (2) changes in the acrosome (acrosome reaction) are closely associated with sperm capacitation; (3) a sharp increase in sperm motility is a characteristic feature of the capacitated spermatozoa.

Time of penetration of capacitated spermatozoa into the egg

To determine how quickly capacitated spermatozoa start to penetrate the 


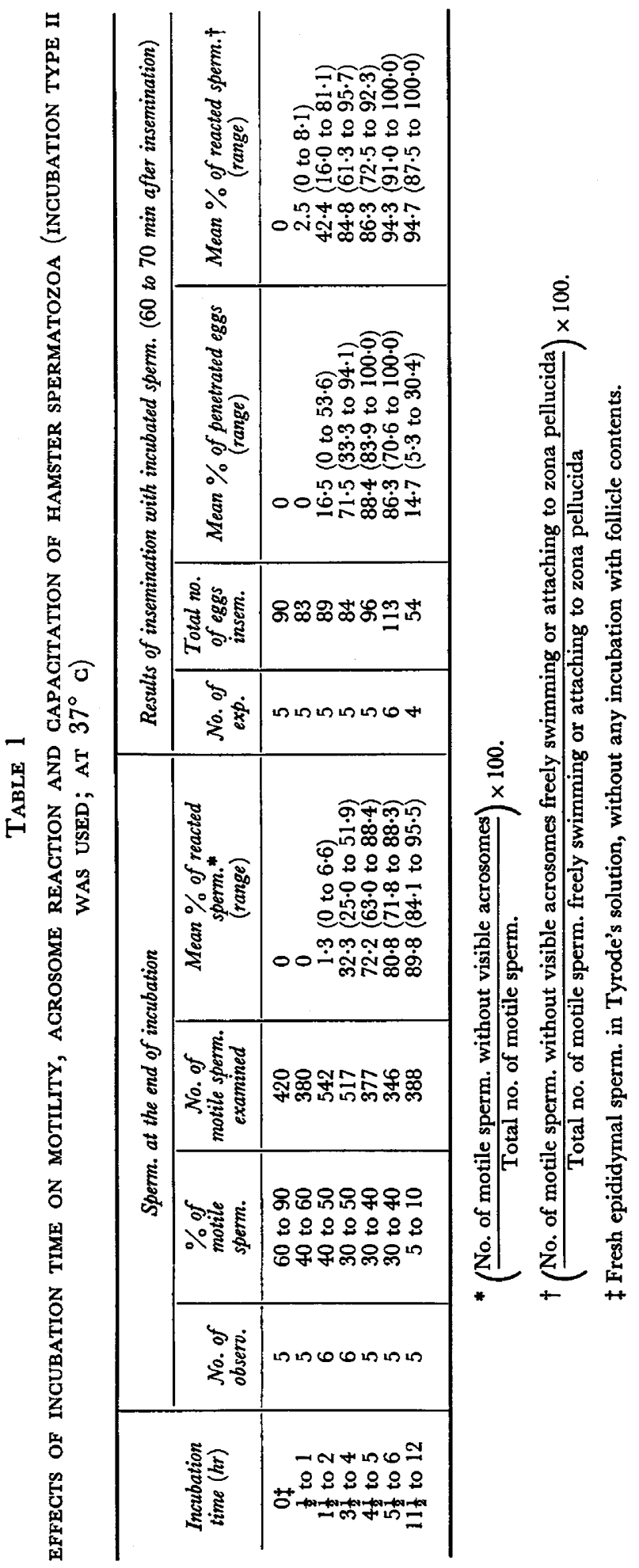


eggs, freshly ovulated eggs were inseminated with capacitated spermatozoa and examined at intervals for sperm penetration. The spermatozoa which had been previously incubated for 4 to $5 \mathrm{hr}$ in the presence of hamster follicle contents (Type II incubation) were used in these experiments.

By 2 to $4 \mathrm{~min}$ after insemination, the cumulus masses were broken up and many spermatozoa came into intimate contact with the zona pellucida of the eggs. The eggs were rotated by the vigorous movement of the attached spermatozoa. Sperm heads embedded in the thickness of the zona pellucida could be seen as early as $10 \mathrm{~min}$ after insemination. By 15 to $25 \mathrm{~min}$ after insemination, some eggs had sperm heads lying on the vitelline surface. In most cases, however, sperm penetration through the zona pellucida occurred between 30 and $50 \mathrm{~min}$ after insemination.

TABLE 2

CAPACITATION OF HAMSTER SPERMATOZOA IN THE PRESENGE OF VARIOUS GOMPONENTS OF HAMSTER FOLLICLE CONTENTS (INCUBATION TIME: $4 \frac{1}{2}$ TO 5 HR AT $37^{\circ} \mathrm{c}$ )

\begin{tabular}{|c|c|c|c|c|c|c|c|c|c|c|}
\hline \multirow{2}{*}{$\begin{array}{c}\text { Type of } \\
\text { incubation }\end{array}$} & \multicolumn{6}{|c|}{$\begin{array}{l}\text { Substances present in } \\
\text { incubation medium* }\end{array}$} & \multirow{2}{*}{$\begin{array}{l}\% \text { of motile } \\
\text { sperm. at the } \\
\text { end of } \\
\text { incubation }\end{array}$} & \multicolumn{3}{|c|}{$\begin{array}{l}\text { Results of insemination with incubated } \\
\text { sperm. }(60 \text { to } 70 \text { min after insemination })\end{array}$} \\
\hline & If & co & $m c o$ & $c r$ & $e$ & $t$ & & $\begin{array}{l}\text { No. of } \\
\text { exp. }\end{array}$ & $\begin{array}{l}\text { Total no. } \\
\text { of eggs } \\
\text { insem. }\end{array}$ & $\begin{array}{c}\text { Mean } \% \text { of penetrated } \\
\text { eggs } \\
\text { (range) }\end{array}$ \\
\hline $\begin{array}{l}\text { I } \\
\text { II } \\
\text { IIIa } \\
\text { IIIb } \\
\text { IIIc } \\
\text { IV } \\
\text { V } \\
\text { Control† }\end{array}$ & $\begin{array}{l}+ \\
+ \\
+ \\
+ \\
+ \\
- \\
-\end{array}$ & $\begin{array}{l}+ \\
+ \\
- \\
- \\
+ \\
+\end{array}$ & $\begin{array}{l}+ \\
+ \\
- \\
- \\
+ \\
+ \\
-\end{array}$ & $\begin{array}{l} \pm \\
- \\
\pm \\
\pm \\
\pm \\
-\end{array}$ & $\begin{array}{l} \pm \\
\overline{-} \\
\bar{t} \\
\overline{-}\end{array}$ & $\begin{array}{l}+ \\
+ \\
+ \\
+ \\
+ \\
+ \\
+ \\
+\end{array}$ & $\begin{array}{l}20 \text { to } 50 \\
20 \text { to } 50 \\
20 \text { to } 50 \\
10 \text { to } 40 \\
10 \text { to } 40 \\
10 \text { to } 30 \ddagger \\
10 \text { to } 30 \ddagger \\
5 \text { to } 20 \ddagger\end{array}$ & $\begin{array}{l}6 \\
5 \\
5 \\
4 \\
5 \\
8 \\
5 \\
5\end{array}$ & $\begin{array}{r}88 \\
68 \\
55 \\
49 \\
56 \\
133 \\
52 \\
67\end{array}$ & $\begin{array}{l}63 \cdot 0(50 \cdot 8 \text { to } 71 \cdot 4) \\
79 \cdot 7(42.9 \text { to } 100 \cdot 0) \\
76 \cdot 7(46 \cdot 2 \text { to } 100 \cdot 0) \\
29 \cdot 0(0 \text { to } 50 \cdot 0) \\
18 \cdot 3(0 \text { to } 75 \cdot 0) \\
0 \\
0 \\
0\end{array}$ \\
\hline
\end{tabular}

* Abbreviations of substances: ff, follicular fluid; co, cumulus oophorus cells; mco, matrix of cumulus oophorus cells; $c r$, corona radiata cells; $e$, eggs; t t Tyrode's solution.

† Epididymal spermatozoa suspended in Tyrode's solution; incubated for $4 \frac{1}{2}$ to $5 \mathrm{hr}$ under mineral oil at $37^{\circ} \mathbf{C}$.

$\ddagger$ Vigorous motility characteristic of the capacitated spermatozoa was not observed.

In some experiments, the eggs were treated with $0.05 \%$ bovine hyaluronidase in Tyrode's solution (to disperse the cumulus mass surrounding the eggs) and rinsed thoroughly with fresh Tyrode's solution (to remove dispersed cumulus cells, their dissolved matrix and oviduct fluid) before they were mixed with spermatozoa. Sperm penetration into such eggs also took place most often between 30 and $50 \mathrm{~min}$ after insemination.

\section{Sperm-capacitating potency of various follicular components}

Follicle contents released from mature ovarian follicles consist of at least five components: (1) follicular fluid, (2) cumulus oophorus cells, (3) their matrix, (4) corona radiata cells, and (5) eggs. To determine if all of these components have a potency to capacitate spermatozoa, the spermatozoa were incubated in the medium with various combinations of these components.

The results (Table 2) clearly showed that only follicular fluid could effectively 
capacitate the spermatozoa. Coexistence of cumulus oophorus cells and their dissolved matrix with follicular fluid apparently did not seriously affect the sperm-capacitating potency of the follicular fluid. It is to be noted that the follicular fluid markedly reduced its sperm-capacitating potency when it was diluted with a large volume of Tyrode's solution (cf. the results of incubation, Type IIIb, c). An efficient capacitation of the spermatozoa seems to occur only when a high concentration of follicular fluid is present in the incubation medium.

Capacitation of hamster spermatozoa by follicular fuids of foreign species

To determine if hamster spermatozoa can be capacitated by follicular fluids of other species, the spermatozoa were incubated with follicular fluids of rats, mice and rabbits. The results (Table 3 ) showed that mouse follicular fluid could

TABLE 3

GAPACITATION OF HAMSTER SPERMATOZOA BY FOLLIGULAR FLUIDS OF THE MOUSE, RAT AND RABBIT (INCUBATION TIME: $5 \frac{1}{2}$ TO 6 HR AT $37^{\circ} \mathrm{c}$ )

\begin{tabular}{|c|c|c|c|c|c|}
\hline \multirow{2}{*}{ Species } & \multirow{2}{*}{$\begin{array}{l}\text { Type of } \\
\text { incubation } \\
\text { used }\end{array}$} & \multirow{2}{*}{$\begin{array}{c}\% \text { of motile sperm. } \\
\text { at the end of } \\
\text { incubation }\end{array}$} & \multicolumn{3}{|c|}{$\begin{array}{l}\text { Results of insemination with incubated sperm. } \\
\quad(60 \text { to } 70 \text { min after insemination })\end{array}$} \\
\hline & & & $\begin{array}{l}\text { No. of } \\
\text { exp. }\end{array}$ & $\begin{array}{c}\text { Total no. of } \\
\text { eggs inseminated }\end{array}$ & Mean $\%$ of penetrated eggs \\
\hline Mouse & $\begin{array}{l}\text { I } \\
\text { II }\end{array}$ & $\begin{array}{l}25 \text { to } 40 \\
25 \text { to } 40\end{array}$ & $\begin{array}{l}4 \\
3\end{array}$ & $\begin{array}{l}48 \\
31\end{array}$ & $\begin{array}{l}35 \cdot 8(14 \cdot 3 \text { to } 76 \cdot 9) \\
61 \cdot 3(26.7 \text { to } 100 \cdot 0)\end{array}$ \\
\hline Rat & $\begin{array}{l}\text { I } \\
\text { II }\end{array}$ & $\begin{array}{l}5 \text { to } 10 \\
5 \text { to } 25\end{array}$ & $\begin{array}{l}3 \\
3\end{array}$ & $\begin{array}{l}35 \\
32\end{array}$ & $\begin{array}{l}4 \cdot 8(0 \text { to } 14 \cdot 3) \\
9 \cdot 1(7 \cdot 1 \text { to } 11 \cdot 1)\end{array}$ \\
\hline Rabbit & II & $0^{*}$ & 3 & 34 & 0 \\
\hline
\end{tabular}

* All the spermatozoa became immotile within $1 \mathrm{hr}$ of the start of incubation.

capacitate hamster spermatozoa to a fairly good extent, whereas rat follicular fluid could scarcely do it. Rabbit follicular fluid was totally ineffective.

It is to be noted that the motility of the hamster spermatozoa is sustained much better in the presence of mouse follicular fluid than in the presence of rat or rabbit follicular fluids. The failure of rat and rabbit follicular fluids to capacitate hamster spermatozoa seems to be correlated with their inability to sustain the viability of the hamster spermatozoa.

\section{DISCUSSION}

Role of follicular fluid in sperm capacitation

In the hamster, the ovaries are completely surrounded by the ovarian bursa (Glewe, 1965). It is highly probable that at least a part of the follicular fluid released from ovarian follicles during ovulation is transported into the oviduct where it mixes with the fluid secreted from the oviduct wall (oviduct fluid). A strong sperm-capacitating ability of the follicular fluid as demonstrated in this study suggests that this substance takes part in the capacitation of hamster spermatozoa in vivo. The finding by Barros \& Austin (1967b) that hamster 
follicular fluid has a stronger acrosome reaction-inducing potency than oviduct fluid suggests that the follicular fluid contains more sperm-capacitating factors than oviduct fluid. This, however, does not necessarily imply that follicular fluid is more important than oviduct fluid in the capacitation of spermatozoa. It seems more plausible that both follicular fluid and oviduct fluid play equally important roles in the capacitation of spermatozoa. These two kinds of fluids with different origins must have common sperm-capacitating factors and work synergistically in capacitating the spermatozoa in vivo.

Restall (1964) has reported that the metabolism of ram spermatozoa is increased considerably following incubation with the fluids from the cervicovagina, uterus, oviduct and ovarian follicle. He has expressed the opinion that the follicular fluid may assist the process of sperm capacitation in the female genital tract.

\section{Time required for sperm capacitation in vitro}

It has been inferred from studies on the time-relationship between mating of females and sperm penetration into the eggs that hamster spermatozoa need 2 to $4 \mathrm{hr}$ to be capacitated in vivo (Strauss, 1956; Chang \& Sheaffer, 1957; Yanagimachi, 1966). Under the present experimental (in vitro) conditions, some spermatozoa were capacitated as early as about $2 \mathrm{hr}$ after the start of incubation. Most of the spermatozoa, however, were capacitated only when they had been incubated for about $3 \mathrm{hr}$ or longer. The coincidence of the time required for sperm capacitation in vivo and in vitro suggests that the mechanisms or processes by which the hamster spermatozoa were capacitated were substantially the same both in vivo and in vitro.

\section{Some characteristics of capacitated hamster spermatozoa}

In the great majority of spermatozoa believed to have been capacitated in vitro, the acrosome was invisible under the phase-contrast microscope. The disappearance of the acrosome in capacitated spermatozoa seems to be due to an extensive disintegration of this structure (detachment or vesiculation of the acrosome cap: Austin \& Bishop, 1958a, b; Barros, Bedford, Franklin \& Austin, 1967; Bedford, 1967a). Although the acrosome was visible in some of the capacitated spermatozoa, it soon disappeared after the spermatozoa were placed in immediate contact with freshly ovulated eggs. All the spermatozoa which were about to enter the zona pellucida or in the act of penetration through the zona pellucida were devoid of this structure. The importance of the alteration (disintegration) of the acrosome as a step of sperm capacitation in the hamster (Austin \& Bishop, 1958b; Austin \& Walton, 1960) was thus confirmed. At least in the hamster, a complete disintegration of the acrosome cap (outer acrosome membrane and overlying sperm plasma membrane) and the exposure of the inner acrosome membrane (and underlying perforatorium) seems to be an essential preliminary to sperm passage through the zona pellucida of the egg. Such an acrosomal change must represent the final phase of sperm capacitation.

An increased motility was another characteristic feature of the capacitated spermatozoa. The swimming rate and the frequency of flagellum beating was 
apparently far greater in the capacitated spermatozoa than in uncapacitated ones. The vigorous beating of the flagellum, which undoubtedly provides more propelling power to the spermatozoon, must play a vital role in enabling the spermatozoon to penetrate the structure of zona pellucida. In fact, Yanagimachi (1966) observed a vigorous motion of the sperm flagellum as the spermatozoon travelled through the zona pellucida of the hamster egg.

Rabbit spermatozoa have been most often used for the study of capacitation, but so far no one has noticed an increased motility of the capacitated spermatozoa. On the other hand, it has been demonstrated that incubation of the spermatozoa in the female genital tract for several hours markedly stimulates the respiration $\left(\mathrm{O}_{2}\right.$ uptake) or metabolism (glucose utilization and lactate production) of the spermatozoa (Hamner \& Williams, 1963; Mounib \& Chang, 1964). These workers presumed that the increased metabolism of the spermatozoa was associated with sperm capacitation. The present author infers that sperm capacitation occurs in conjunction with an increased permeability of the sperm plasma membrane. An increased permeability of the plasma membrane overlying the acrosome system, which eventually results in the disintegration of the membrane, would allow the hyaluronidase in the acrosome to escape out of the system. An increased permeability of the membrane covering the middle piece and flagellum would possibly promote the entrance of exogenous substrates into the sperm cell, resulting in an increased motility or metabolism of the spermatozoon.

Bedford (1967b) has presented evidence that the fertile life of capacitated rabbit spermatozoa is considerably shorter than that of uncapacitated ones. The reduction of length of life of capacitated spermatozoa may be due to a quick exhaustion of endogenous substrates in the sperm cell.

\section{Polyspermic fertilization of eggs by capacitated spermatozoa}

The great majority of the hamster eggs inseminated with capacitated spermatozoa under the present experimental conditions was penetrated by more than one spermatozoon. Penetration of more than ten spermatozoa into one egg was fairly common. Barros \& Austin (1967a), who inseminated hamster eggs with epididymal spermatozoa in the presence of follicular fluid, also noticed a high incidence of polyspermic fertilization. This high incidence of polyspermy appears to be due to the presence of too many capacitated spermatozoa around the eggs at the time of fertilization. The polyspermy-blocking action of the zona pellucida (zona reaction), which is believed to be highly efficient in the hamster (Austin \& Braden, 1956; Austin \& Walton, 1960) apparently does not work quickly enough when there are too many capacitated spermatozoa around the eggs. We would be able to avoid such a high incidence of polyspermic fertilization of the eggs only when we properly control the number of capacitated spermatozoa around the eggs.

Species-specificity of sperm-capacitating factors in follicular fluid

The data of the present study showed that hamster spermatozoa may be capacitated in vitro by follicular fluids from other species such as the rat and the mouse. Follicular fluid of the mouse could capacitate hamster spermatozoa to a 
fairly good extent, but its potency was not as high as that of the hamster follicular fluid. Rat follicular fluid had only a slight potency to capacitate hamster spermatozoa. The three species studied can be arranged in the following order according to the potency of follicular fluid to capacitate hamster spermatozoa: hamster $>$ mouse $>$ rat. Rabbit follicular fluid was totally ineffective in these respects.

It is interesting that the sperm-capacitating potency of follicular fluid is closely related to its ability to maintain the viability of spermatozoa. Hamster follicular fluid was most potent in both sustaining viability and capacitating hamster spermatozoa. Rabbit follicular fluid, on the contrary, was least potent in these respects.

\section{ADDENDUM}

After the manuscript of this paper had been submitted to the editor, a full report of the work by Barros \& Austin was published (7. exp. Zool. 166, 317, 1967). In addition to the facts described in their preliminary reports, Barros \& Austin reported that: (1) in vitro capacitation of hamster spermatozoa needs about $4 \mathrm{hr}$, (2) the efficiency of polyspermy-blocking mechanisms in the hamster egg increases during preovulatory follicular enlargement to reach a peak during the first 2 to $3 \mathrm{hr}$ after ovulation, and (3) the induction of the acrosome reaction by tubal fluid (a mixture of follicular fluid and secretion from the oviduct wall) shows some degree of species-specificity (mouse tubal fluid is slightly more potent than rat tubal fluid in inducing the acrosome reaction of hamster spermatozoa, but is far less potent than hamster tubal fluid).

The present author has found (unpublished) that the follicular fluid in growing, immature follicles of the hamster (about 12 to $36 \mathrm{hr}$ before ovulation) is far less potent than the fluid in mature follicles (a few hours before ovulation) both in sustaining sperm motility and in inducing the acrosome reaction of hamster spermatozoa. The fluid in immature follicles was apparently less viscous than the fluid in mature follicles. The fluids in both immature and mature follicles, however, showed almost the same degree of metachromatic reaction (toluidine blue).

\section{ACKNOWLEDGMENTS}

The author is indebted to Dr R. W. Noyes for his active interest and advice. Thanks are also due to Dr G. S. Greenwald for his kind suggestion of the possibility of the induction of precocious ovulation in the adult hamster by injection of HCG on Day 3.

The work was supported by grants from the U.S. Public Health Service (HD 02066-02 and 03402-01), the Ford Foundation and the University of Hawaii Intramural Research Program.

\section{REFERENCES}

Austin, G. R. \& Bishop, M. W. H. (1958a) Some features of the acrosome and perforatorium in mammalian spermatozoa. Proc. R. Soc. B, 148, 234. 
Austin, C. R. \& Bishop, M. W. H. (1958b) Role of the rodent acrosome and perforatorium in fertilization. Proc. R. Soc. B, 148, 241.

Austin, C. R. \& BRADEN, A. W. H. (1956) Early reactions of the rodent egg to spermatozoon penetration. F. exp. Biol. 33, 358.

Ausrin, C. R. \& Walton, A. (1960) Fertilization. In: Marshall's Physiology of Reproduction, Vol. 1(2), p. 310. Ed. A. S. Parkes. Longmans Green, London.

Barros, C. \& Austin, C. R. (1967a) In vitro fertilization of golden hamster ova. Anat. Rec. 157, 209.

Barros, C. \& Austin, C. R. (1967b) In vitro acrosomal reaction of golden hamster spermatozoa. Anat. Rec. 157, 348.

Barros, C., Bedford, J. M., Frankin, L. E. \& Austin, C. R. (1967) Membrane vesiculation as a feature of the mammalian acrosome reaction. F. Cell Biol. 34, C 1.

BEDFoRd, J. M. (1967a) Experimental requirement for capacitation and observations on ultra-structural changes in rabbit spermatozoa during fertilization. F. Reprod. Fert., Suppl. 2, 35.

BEDford, J. M. (1967b) Fertile life of rabbit spermatozoa in rat uterus. Nature, Lond. 213, 1097.

Chang, M. C. \& Sheaffer, D. (1957) Number of spermatozoa ejaculated at copulation, transported into the female tract, and present in the male tract of the golden hamster. 7 . Hered. $48,107$.

CLEWE, T. H. (1965) Absence of a foramen in the ovarian bursa of the golden hamster. Anat. Rec. 151, 446.

HAMNER, G. E. \& WiLLIAMs, W. L. (1963) Effect of the female reproductive tract on sperm metabolism in the rabbit and fowl. F. Reprod. Fert. 5, 143.

Mounib, M. S. \& Chang, M. G. (1964) Effect of in utero incubation on the metabolism of rabbit spermatozoa. Nature, Lond. 201, 943.

Restall, B. J. (1964) Effect of genital fuids of the ewe on the metabolism of ram spermatozoa. In: Proc. 5th Biennial Conf. Aust. Soc. Anim. Prod., Sydney. p. 29. Ramsey, Ware Publishing, Australia. Cited from Bibl. of Reprod. 10.

Strauss, F. (1956) The time and place of fertilization of the golden hamster egg. F. Embryol. exp. Morph. 4, 42.

YANAGIMACHI, R. (1966) Time and process of sperm penetration into hamster ova in vivo and in vitro. 7. Reprod. Fert. 11, 359.

Yanagimachi, R. \& Chang, M. C. (1964) In vitro fertilization of hamster ova. J. exp. Zool. 156, 361. 